\title{
The Disgust Propensity and Sensitivity Scale - Revised: Its predictive value for avoidance behavior
}

Citation for published version (APA):

van Overveld, M., de Jong, P. J. ., \& Peters, M. L. (2010). The Disgust Propensity and Sensitivity Scale Revised: Its predictive value for avoidance behavior. Personality and Individual Differences, 49(7), 706711. https://doi.org/10.1016/j.paid.2010.06.008

Document status and date:

Published: 01/11/2010

DOI:

10.1016/j.paid.2010.06.008

Document Version:

Publisher's PDF, also known as Version of record

\section{Document license:}

Taverne

\section{Please check the document version of this publication:}

- A submitted manuscript is the version of the article upon submission and before peer-review. There can be important differences between the submitted version and the official published version of record.

People interested in the research are advised to contact the author for the final version of the publication, or visit the DOI to the publisher's website.

- The final author version and the galley proof are versions of the publication after peer review.

- The final published version features the final layout of the paper including the volume, issue and page numbers.

Link to publication

\footnotetext{
General rights rights.

- You may freely distribute the URL identifying the publication in the public portal. please follow below link for the End User Agreement:

www.umlib.nl/taverne-license

Take down policy

If you believe that this document breaches copyright please contact us at:

repository@maastrichtuniversity.nl

providing details and we will investigate your claim.
}

Copyright and moral rights for the publications made accessible in the public portal are retained by the authors and/or other copyright owners and it is a condition of accessing publications that users recognise and abide by the legal requirements associated with these

- Users may download and print one copy of any publication from the public portal for the purpose of private study or research.

- You may not further distribute the material or use it for any profit-making activity or commercial gain

If the publication is distributed under the terms of Article $25 \mathrm{fa}$ of the Dutch Copyright Act, indicated by the "Taverne" license above, 


\title{
The Disgust Propensity and Sensitivity Scale - Revised: Its predictive value for avoidance behavior
}

\author{
Mark van Overveld $^{\mathrm{a}, *}$, Peter J. de Jong ${ }^{\mathrm{b}}$, Madelon L. Peters ${ }^{\mathrm{a}, 1}$ \\ ${ }^{a}$ Marketing Management, Erasmus University Rotterdam, P.O. Box 1738, 3000 DR Rotterdam, The Netherlands \\ ${ }^{\mathrm{b}}$ Department of Clinical and Developmental Psychology, University of Groningen, The Netherlands
}

\section{A R T I C L E I N F O}

\section{Article history:}

Received 27 July 2009

Received in revised form 19 April 2010

Accepted 10 June 2010

Available online 15 July 2010

\section{Keywords:}

Disgust propensity

Disgust sensitivity

Validity

Behavioral validation

Behavioral experiments

\begin{abstract}
A B S T R A C T
Disgust propensity appears involved in psychopathology. However, current disgust propensity indices display inflated correlations with psychopathology indices due to conceptual overlap. The recently developed Disgust Propensity and Sensitivity Scale - Revised (DPSS-R) is unique in that it measures disgust propensity irrespective of specific elicitors. Although psychometric research confirmed its factor-structure, its predictive validity remains to be established. Therefore, the goal of this study is to test its predictive validity for avoidance behavior in a series of disgusting tasks. Preselected participants $(N=60)$ with varying levels of disgust propensity engaged in seventeen behavioral tasks. Supporting its predictive validity, higher DPSS-R scores were associated with completing fewer behavioral actions. Additionally, the DPSS-R had added predictive value over and above traditional trait disgust indices.
\end{abstract}

Crown Copyright @ 2010 Published by Elsevier Ltd. All rights reserved.

\section{Introduction}

Accumulating evidence suggests that disgust propensity, the tendency to experience disgust more readily, is involved in psychopathology, like spider phobia (Matchett \& Davey, 1991), blood phobia (Page, 1994), and sexual dysfunctions (de Jong, van Overveld, Weijmar Schultz, Peters, \& Buwalda, 2009).

However, associations between disgust propensity and psychopathology may present an artifact as current disgust indices contain conceptual overlap with indices of psychopathology. For example, the Disgust Scale (DS; Haidt, McCauley, \& Rozin, 1994), Disgust Questionnaire (DQ; Rozin, Fallon, \& Mandell, 1984), and Disgust Emotion Scale (DES; Walls \& Kleinknecht, 1996) assess disgust propensity in relation to specific objects. Thus, artificially inflated relationships may occur with psychopathology indices as both contain similar items (e.g., small animals). This underlines the importance of a disgust propensity index that does not rely on particular disgust elicitors. Further, for cross-cultural comparisons, such a measure would be helpful as disgust-eliciting properties vary across cultures (e.g., Olatunji et al., 2009).

The Disgust Propensity and Sensitivity Scale (DPSS) is the first index to measure disgust propensity irrespective of disgust elicitors (Cavanagh \& Davey, 2000). Additionally, it measures disgust sensitivity. In the context of psychopathology, it may both be

\footnotetext{
* Corresponding author. Tel.: +310 10 4081970; fax: +31 0104089572.

E-mail address: MOverveld@RSM.nl (M. van Overveld).

${ }^{1}$ Clinical Psychological Science, Maastricht University, The Netherlands.
}

important how readily people respond with disgust (disgust propensity), and how unpleasant people consider experiencing disgust (disgust sensitivity). High levels of disgust propensity may enlarge the probability that stimuli acquire a disgust-evoking status. If the (subjective) probability of unwilling physical contact with disgusting stimuli is high, this may lead to phobic fear and avoidance (e.g., de Jong \& Muris, 2002). This may be especially pronounced in individuals who consider experiencing disgust highly aversive (e.g., van Overveld, de Jong, Peters, van Hout, \& Bouman, 2008).

The revised DPSS-R demonstrated good psychometric qualities in terms of internal consistency and factor-structure (Olatunji, Cisler, Deacon, Connolly, \& Lohr, 2007a; van Overveld, de Jong, Peters, Cavanagh, \& Davey, 2006). Recently, its psychometric qualities were refined even further (Fergus \& Valentiner, 2009). An important next step is to test its predictive validity. Hence, the present study investigates predictive validity of the DPSS-R for actual avoidance behavior and subjective experiences of disgust (cf. Rozin, Haidt, McCauley, Dunlop, \& Ashmore, 1999). To explore the predictive value of the Disgust Propensity and Sensitivity Scale Revised compared to traditional indices, participants also completed the Disgust Scale (DS), Disgust Emotion Scale (DES), and Disgust Questionnaire (DQ).

Disgust propensity (indexed by DS) has already been associated with performance on various disgusting behavioral avoidance tasks (BAT; Deacon \& Olatunji, 2007). Further, blood phobic individuals with enhanced disgust propensity (DES) were less compliant to complete various disgusting BATs (e.g., touching a bloody gauze; Koch, O’Neill, Sawchuk, \& Connolly, 2002) than non-phobic 
participants. Given that the traditional indices examine specific disgust domains, we expected that the DQ (core-disgust; Mulkens, de Jong, \& Merckelbach, 1996), DES (core/AR; Olatunji, Williams, Lohr, \& Sawchuk, 2005), and DS (all domains; Haidt et al., 1994) would be associated strongest with avoidance for the BATs in their respective disgust domain due to content overlap. Accordingly, we anticipated elevated levels of disgust propensity (indexed by Disgust Propensity and Sensitivity - Revised Propensity; DPSS-RP) to be associated with stronger behavioral avoidance and increases in state disgust irrespective of the disgust domain. Finally, we anticipated that disgust sensitivity (Disgust Propensity and Sensitivity - Revised Sensitivity; DPSS-RS) would also be associated with avoidance tendencies. Especially individuals who are prone to experiencing disgust and consider disgust highly unpleasant may be prone to disgust-induced behavioral avoidance.

\section{Methods}

\subsection{Participants}

Students at the schools of Health Sciences, Medicine, and Psychology from Maastricht University completed the DPSS-R and indicated their willingness to participate in a follow-up study. To ensure that scores across a broad range of the DPSS-R were included, the research population $(N=216)$ was divided into deciles and we attempted to include equal numbers of participants per decile. Sixty participants were invited to the lab. As female students are overrepresented at these schools, the research population consists mostly of female participants (52 women; $86.7 \%$ ) with a mean age of 21.58 years ( $S D=2.95$; range: $18-39$ years).

\subsection{Instruments}

Disgust Propensity and Sensitivity Scale - Revised (DPSS-R; van Overveld et al., 2006). The DPSS-R measures disgust propensity and sensitivity. Here, the shortened version was used (Fergus \& Valentiner, 2009). Participants read twelve propositions on disgust propensity (e.g., "I experience disgust") and sensitivity (e.g., "It scares me when I feel faint") and indicated which applied best to them on a scale from 1 (='never') to 5 (='always'; range: $12-60)$. In accordance with commonly used guidelines for interpreting Cronbach's alpha (e.g., Bland \& Altman, 1997), it is internally consistent $(\alpha=.78$ for Propensity, $\alpha=.79$ for Sensitivity; Fergus \& Valentiner, 2009).

Disgust Emotion Scale (DES; Walls, 1996); The DES examines disgust propensity for thirty disgust elicitors. Participants rate how much disgust they experience upon confrontation with thirty items (e.g., vomit smell) on a scale from 0 (='No disgust at all') to 4 (='Extreme disgust'). Here, only the total score was calculated, which was internally consistent $(\alpha=.92)$.

Disgust Questionnaire (DQ; Rozin et al., 1984); The DQ measures propensity for core disgust. It assesses the tendency to reject desirable and edible food items after contamination by disgusting stimuli. Participants indicate on a scale from 1-9 ( $1=$ 'not at all', $9=$ 'very much') their preference towards eating these contaminated foods. A total score can be calculated (range 24-216). Internal consistency is good ( $\alpha=.80$, Mulkens et al., 1996).

Disgust Scale (DS; Haidt et al., 1994). The DS measures disgust propensity for various disgust elicitors and consists of two parts. First, participants rate their agreement with 16 propositions using a dichotomous scoring format ( $0=$ 'false', $1=$ 'true'). Second, participants indicate whether they consider 16 items disgusting on a scale from 0 (='not disgusting at all') to 2 (='extremely disgusting'). Although the 32 -item version was administered, in accordance with recent suggestions (Olatunji et al., 2007b), only 25 items were used to calculate a total score and subscales: Core disgust, AnimalReminder disgust (AR), and Contamination. These are internally consistent (all $\alpha$ 's $>0.70$; Olatunji et al., 2007b) and are favoured above the original eight-factor distribution of the full 32-items DS.

Visual Analog Scale (VAS). participants rated on 100-mm VAS's the levels of state disgust (how much disgust did you experience during this last step?).

\subsection{Materials}

Behavioral Approach Tests; A total of 17 BATs were devised (see Table 1). Four tests were designed for all disgust domains that are generally accepted in disgust research (Rozin, Haidt, \& McCauley, 2009): core, AR, IP, and SM-disgust. Although some tests were derived from previous research (Rozin et al., 1999), most were devised by the current authors. Each test consisted of three steps that gradually increased in disgustingness. The experimenter noted the last completed step $(0=$ 'no step completed at all', $3=$ 'all steps completed'; range $=0-51$ ). The order in which the tests were administered were randomized and then given a fixed order. Thus, the order was similar for all participants $(0,16,7,13,4,15,1,6,11,12$, $10,14,3,5,9,2,8)$.

\subsection{Procedure}

Upon arrival at the lab, participants completed Dutch versions of the DPSS-R, DS, DQ and DES. These were distributed in this order for all participants. Next, informed consent was obtained. Following, participants engaged in the BATs. After each BAT-step, participants completed the VAS-scales. Finally, participants were debriefed and received ten euros.

\subsection{Data reduction}

For the BATs, both the number of total steps completed was calculated (range 0-51) and the mean number of steps for each dis-

Table 1

Summary of the behavioral experiments.

\begin{tabular}{ll}
\hline Neutral & Experiment \\
\hline 0. Stirring water with a finger \\
1. Drinking from a dog's bowl \\
2. Taking a bite from a cookie placed in a jar containing \\
dead grasshoppers \\
3. Touching a live worm with one's lips \\
4. Drinking juice from a glass in which an ice cube \\
containing a dead grasshopper has been dipped \\
Animal-reminder
\end{tabular}


gust domain (range 0-3). For state disgust, mean VAS-scores of the first step were calculated per domain and overall. We used the scores of the first step of each BAT for comparability reasons (only for the first steps it yields that all participants engaged in these steps). Not only were the data complete for these steps, scoring on the first step was also independent of the total number of steps that participants eventually completed.

\section{Results}

\subsection{Descriptives}

Table 2 presents the means, standard deviations, and Cronbach's alpha of the questionnaires and BAT-scores for all participants. With the exception of two subscales of the DS (i.e., AR and contamination), all questionnaires and BATs were internally consistent. $^{2}$ Given the low reliability of the DS-scales that renders meaningful interpretation difficult, further analyses only incorporated the internally consistent DS-total score.

\subsection{State disgust}

To ensure that the BATs successfully elicited disgust, participants' mean state disgust levels were calculated for BATs overall and per domain. Table 3 presents the means of state disgust of the first step for each BAT and per domain (Core, AR, IP, SM).

Paired-sample, one-sided $t$-tests showed a significant increase in all participants in experienced disgust during the first step compared to the neutral BAT for all BATs (all p's <.10).

\subsection{Correlation between trait and state disgust indices during BATs}

Table 4 shows that the correlation between disgust propensity (DPSS-RP) and sensitivity (DPSS-RS) was substantial ( $r=.60)$. Next, bivariate correlations were computed between the DPSS-R and mean state disgust during the first step of each BAT. ${ }^{3}$

Similar to the DES, DS, DQ, the DPSS-R correlated low to moderately with overall mean experienced disgust. All disgust propensity indices displayed similar correlations with disgust during Core, AR, and IP-BATs. Correlations with the SM-domain were virtually absent for all indices. The strength of the associations with experienced disgust was similar for disgust propensity (DPSS-RP) and sensitivity (DPSS-RS).

\subsection{Correlations between trait disgust and disgust avoidance}

Table 5 shows that disgust propensity (DPSS-RP) had predictive value for the overall number of BAT-steps completed. Its predictive value was comparable to other disgust propensity instruments (DS, DQ DES). Disgust sensitivity (DPSS-RS) did not correlate significantly with overall BAT-performance $(p=-.19)$, but correlated significantly with AR-BAT-performance $(p<.05)$ and approached significance for the core-BATs $(p=.07)$. As expected, the DQ correlated most strongly with core-BAT-performance, together with DPSS-RP. Next, AR-BAT-performance correlated significantly with DPSS-R, DES and DS. Performance on the IP-BATs correlated significantly with all disgust propensity indices except for the DPSS-R,

\footnotetext{
2 Regression analyses for the DS-scales to predict domain-related BAT-performance (core/AR) revealed that only DS-contamination significantly predicted Core and ARBAT-performance (both $p$ 's $<.04$ ). DS-core was not associated more strongly than other subscales with Core-BAT-performance, or DS-AR with performance on AR-BATs, so for further analyses, the DS-total score was used.

${ }^{3}$ Attesting to the validity of using state disgust during the first step, results showed high correlations between disgust during the first step and BAT-steps taken overall $(r=.58)$ and per domain ( $r$ 's between .38 and .55$)$.
}

Table 2

Descriptive statistics for indices of disgust propensity (DPSS-RP, DES, DS, DQ), disgust sensitivity (DPSS-RS) and BAT-scores for all participants.

\begin{tabular}{lcrlr}
\hline Indices & Means $(n=60)$ & \multicolumn{1}{c}{ SD } & Range (min-max) & $\alpha$ \\
\hline DPSS-R-total & 25.77 & 5.26 & $15-42(12-60)$ & .70 \\
Propensity & 15.13 & 3.13 & $8-22(6-30)$ & .73 \\
Sensitivity & 10.63 & 3.57 & $6-23(6-30)$ & .60 \\
DES-total & 36.95 & 17.56 & $8-86(0-120)$ & .92 \\
DS-total & 13.25 & 3.30 & $6.5-20.5(0-25)$ & .75 \\
Core & 8.68 & 2.92 & $3-15(0-18)$ & .65 \\
AR & 6.50 & 1.60 & $2-10(0-12)$ & .21 \\
Contamination & 4.23 & 1.42 & $1-7(0-9)$ & .39 \\
DQ-total & 140.68 & 30.48 & $69-207(24-216)$ & .94 \\
BAT-steps taken & 45.53 & 5.06 & $26-51(0-51)$ & .82 \\
Core & 2.58 & .33 & $1.25-3(0-3)$ & .65 \\
AR & 2.70 & .57 & $.5-3(0-3)$ & .78 \\
IP & 2.60 & .44 & $1.25-3(0-3)$ & .73 \\
SM & 2.76 & .40 & $1-3(0-3)$ & .60 \\
Valid $N$ & & & & 60 \\
\hline
\end{tabular}

Abbreviations: DPSS-R = Disgust Propensity and Sensitivity Scale - Revised; $\mathrm{DES}=$ Disgust Emotion Scale; DS = Disgust Scale; $\mathrm{DQ}=$ Disgust Questionnaire; $\mathrm{BAT}=$ behavioral approach task; $\mathrm{AR}=$ animal-reminder disgust; $\mathrm{IP}=$ Interpersonal disgust; $\mathrm{SM}$ = sociomoral disgust.

Table 3

Mean state disgust during the first step of each disgust-BAT and per domain.

\begin{tabular}{lcl}
\hline BAT & ED & Actual range \\
\hline Neutral (water) & $.55(1.33)$ & $0-7$ \\
Core $(\alpha=.65)$ & $7.54(9.47)$ & $0-43$ \\
Ice cube & $8.17(13.87)$ & $0-65$ \\
Dog's bowl & $1.42(3.42)$ & $0-19$ \\
Worm & $10.85(17.20)$ & $0-80$ \\
Cookie & $9.75(15.20)$ & $0-64$ \\
AR $(\alpha=.78)$ & $14.15(14.54)$ & $0-68$ \\
Band aid & $7.33(10.22)$ & $0-53$ \\
Pig's head & $21.57(21.90)$ & $0-85$ \\
Spider crab & $9.05(16.23)$ & $0-84$ \\
Horse's leg & $18.65(22.93)$ & $0-87$ \\
IP $(\alpha=.73)$ & $7.24(8.41)$ & $0-51$ \\
Electrode & $2.68(5.10)$ & $0-27$ \\
Saliva & $6.27(10.38)$ & $0-66$ \\
Hair brush & $7.52(12.46)$ & $0-48$ \\
Dirty towel & $12.50(15.23)$ & $0-65$ \\
SM $(\alpha=.60)$ & $11.77(11.16)$ & $0-41$ \\
Needle doll & $.78(1.54)$ & $0-6$ \\
Robbery film & $17.92(21.52)$ & $0-81$ \\
Horse meat & $4.33(8.60)$ & $0-55$ \\
Phone call film & $24.05(24.98)$ & $0-93$ \\
Total overall $(\alpha=.82)$ & $9.61(8.33)$ & $0-38$ \\
Valid $N$ & & 60 \\
\hline
\end{tabular}

Abbreviations: $\mathrm{BAT}=$ behavioral approach task; Core = core disgust; $\mathrm{AR}=$ animalreminder disgust; $\mathrm{IP}=$ interpersonal disgust; $\mathrm{SM}=$ sociomoral disgust; $\mathrm{ED}=$ experienced disgust

Note: standard deviations are presented in parentheses.

although correlations for the DPSS-R were in the expected direction. None of the disgust indices correlated with SM-BATperformance.

\subsection{Predictive validity}

To determine the relative strength of disgust propensity and sensitivity as predictors of avoidance, hierarchical regression analyses were conducted with the total number of steps as dependent variable and DPSS-R subscales as predictors (method = enter). This allows one to examine whether disgust sensitivity (or the interaction term) adds significant predictive value to disgust propensity in predicting behavioral avoidance during the BATs. First, data were centered to reduce multicollinearity. The centered scores for dis- 
Table 4

Bivariate correlations between disgust indices (DPSS-R, DES, DS, DQ) and mean state disgust (ED) during the first step of each BAT (Core, AR, IP, SM, overall mean total).

\begin{tabular}{lccccc}
\hline Questionnaires & DPSS-RP & DPSS-RS & DES total & DS total & DQ \\
\hline Trait indices & & & & & \\
DPSS-RS & $.60^{* *}$ & & & & \\
DES total & .24 & $.27^{*}$ & & & \\
DS total & $.31^{*}$ & $.42^{* *}$ & $.70^{* *}$ & & \\
DQ & -.18 & $-.27^{*}$ & $-.27^{*}$ & $-.45^{* *}$ & \\
ED & & & & & \\
Core & .15 & .17 & $.35^{* *}$ & $.42^{* *}$ & $-.32^{*}$ \\
AR & $.27^{*}$ & $.27^{* *}$ & $.37^{* *}$ & $.57^{* *}$ & $-.37^{* *}$ \\
IP & $.26^{*}$ & .23 & $.33^{*}$ & $.34^{* *}$ & $-.27^{*}$ \\
SM & .06 & -.01 & .18 & .14 & .04 \\
Total & .24 & .21 & $.38^{* *}$ & $.47^{* *}$ & $-.29^{*}$ \\
Valid N & & & & & \\
\hline
\end{tabular}

Abbreviations: Core = core disgust; $\mathrm{AR}=$ animal-reminder disgust; $\mathrm{IP}=$ interpersonal disgust; $\mathrm{SM}=$ sociomoral disgust; $\mathrm{ED}=$ experienced disgust; $\mathrm{DPSS}-\mathrm{RP}=\mathrm{Dis}-$ gust Propensity and Sensitivity Scale - Revised Propensity; DPSS-RS = Disgust Propensity and Sensitivity Scale - Revised Sensitivity; DS-total = Disgust Scale; DES = Disgust Emotion Scale; DQ = Disgust Questionnaire

* Significant at $p<.05$.

Significant at $p<.01$

Table 5

Bivariate correlations between disgust propensity (DPSS-RP, DES, DS, DQ), disgust sensitivity (DPSS-RS), and the number of BAT-steps taken.

\begin{tabular}{llllll}
\hline Index & Core & AR & P & SM & Total steps \\
\hline DPSS-RP & $-.34^{* *}$ & $-.27^{*}$ & -.20 & .06 & $-.27^{*}$ \\
DPSS-RS & -.23 & $.27^{*}$ & -.06 & .04 & -.19 \\
DES total & -.07 & $-.25^{*}$ & $-.34^{* *}$ & -.16 & $-.30^{*}$ \\
DS total & -.19 & $-.40^{* *}$ & $-.25^{*}$ & -.13 & $-.35^{*}$ \\
DQ & $.42^{* *}$ & .13 & $.34^{* *}$ & -.04 & $.28^{*}$ \\
Valid $N$ & & & & & 60 \\
\hline
\end{tabular}

Abbreviations: Core = core disgust; $\mathrm{AR}=$ animal-reminder; $\mathrm{IP}=$ interpersonal $\mathrm{SM}=$ sociomoral; DPSS-RP = Disgust Propensity and Sensitivity Scale - Revised Propensity; DPSS-RS = Disgust Propensity and Sensitivity Scale - Revised Sensitivity; $\quad$ DS-total = Disgust Scale; $\quad$ DES $=$ Disgust Emotion Scale; $\quad \mathrm{DQ}=$ Disgust Questionnaire.

Significant at $p<.05$.

Significant at $p<.01$.

gust propensity (DPSS-RP) were added in the first step, centered scores of disgust sensitivity (DPSS-RS) in the second step, and the interaction term in the last step. Initially, disgust propensity proved a significant predictor $(\beta=-.50 ; t=-2.10 ; p=.04)$. In the second step $\left(\Delta R^{2}<.01 ; p=.77\right)$, disgust sensitivity did not add significantly to the explained variance $(\beta=-.07 ; t=-.29 ; p=.77)$. Disgust propensity was no longer a significant predictor $(\beta=-.45 ; t=-1.49 ; p=.14)$. In the last step $\left(\Delta R^{2}=.01 ; p=.49\right)$, the interaction term did not significantly predict avoidance behavior $(\beta=-.06 ; t=-.70 ; p=.49)$. So, for behavioral avoidance, a combination of high levels of both propensity and sensitivity may not be essentially required.

\subsection{Predictive validity of DPSS-R compared to other indices}

To examine the relative predictive value of the DPSS-R compared to existing trait indices (DES, DS, DQ), a series of regression analyses (method = backwards) examined which disgust indices (DPSS-R, DES, DQ DS) best predicted behavioral avoidance (number of BAT-steps for Core, AR, IP, and SM). Table 6 shows that for core-disgust BATs, only the DQ and DPSS-RP remained in the final equation as significant predictors (both $p$ 's $<.03$ ). For AR-disgust, only the DS proved a significant predictor $(p<.01)$. IP-disgust BAT-performance was significantly predicted by DES and DQ (both $p$ 's <.05), while for SM disgust, none of the indices proved a signif-
Table 6

Regression analyses for the trait disgust indices (DPSS-R, DES, DS, DQ) as predictors of behavioral avoidance (number of BAT-steps) for all disgust domains.

\begin{tabular}{|c|c|c|c|c|}
\hline & $B$ & SE $B$ & $\beta$ & $p$ \\
\hline \multicolumn{5}{|c|}{ Avoidance tendencies } \\
\hline \multirow[t]{2}{*}{ Total steps } & $R^{2}=.16$ for full model & & & \\
\hline & .52 & .19 & .34 & $<.01$ \\
\hline \multirow[t]{3}{*}{ Core } & $R^{2}=.26$ for full model & & & \\
\hline & DPSS-RP & .06 & -.28 & .02 \\
\hline & DQ & .01 & .35 & $<.01$ \\
\hline \multirow[t]{2}{*}{ AR } & $R^{2}=.19$ for full model & & & \\
\hline & .27 & .08 & .40 & $<.01$ \\
\hline \multirow[t]{3}{*}{ IP } & $R^{2}=.22$ for full model & & & \\
\hline & $\begin{array}{ll}\mathrm{DQ} & .02\end{array}$ & .01 & .27 & .04 \\
\hline & -.02 & .01 & -.26 & .05 \\
\hline \multirow[t]{2}{*}{ SM } & $R^{2}=.04$ for full model & & & \\
\hline & Constant & .20 & - & $<.01$ \\
\hline
\end{tabular}

icant predictor. As expected, the domain-specific indices were associated strongest with BAT-performance. Yet, disgust propensity (DPSS-RP) still appeared of added value to existing indices in the core disgust domain.

\section{Discussion}

The main findings are: (i) trait disgust as indexed by the context-independent DPSS-R showed predictive validity for disgustrelated avoidance and state disgust during prototypical disgustBATs (Core, AR), (ii) the disgust propensity subscale even showed cumulative predictive validity over and above traditional (contextualised) disgust propensity indices for avoidance in the core disgust domain, (iii) disgust sensitivity showed no added predictive value for experienced disgust or BAT-performance.

In line with earlier research (e.g., Fergus \& Valentiner, 2009), the (shortened) DPSS-R was internally consistent. Further, supporting its (convergent) validity, the DPSS-R showed moderate correlations with traditional disgust propensity indices. These moderate correlations indicated that the decontextualised DPSS-R provides complementary information regarding people's disgust propensity that is not restricted to particular predefined disgust elicitors.

We anticipated that elevated levels of disgust propensity and disgust sensitivity would be predictive of less approach behavior in a series of disgusting behavioral tasks. Given the possibility of inflated results due to item overlap, we expected the DQ to be associated with performance on core-disgust BATs, and the DES/DS with multiple disgust domains. The decontextualised DPSS-R was expected to be associated with avoidance across all disgust domains.

Supporting its validity, disgust propensity (DPSS-RP) was indeed associated with a decreased willingness to complete the disgusting behavioral tasks. This replicates earlier findings that higher levels of contextualised disgust propensity (e.g., DS/DES) were associated with individuals' performance on similar behavioral tasks (e.g., touching a used comb, Deacon \& Olatunji, 2007; a bloody gauze; Koch, O’Neill, Sawchuk, \& Connolly, 2002; a worm; Tsao \& McKay, 2004). This is particularly noteworthy since the DPSS-R is the first index to measure disgust propensity irrespective of specific elicitors. So, associations between disgust propensity and behavioral avoidance for specific objects can not be attributed to content overlap.

In accordance with earlier work (Rozin et al., 1999), there appeared congruency between the disgust that people claim to experience when confronted with specific objects (e.g., DES/DS) and what they display upon actual confrontation with them. As expected, domain-specific indices that display overlap with the BATs (DES/DS) or explicitly assess approach behavior towards disgust- 
stimuli (DQ) were associated strongest with BAT-performance. Predictive validity of the DPSS-R was restricted to BAT-performance in prototypical disgust domains (core/AR). Thus, the DPSS$\mathrm{R}$ appears of added value to the traditional indices in that it predicts avoidance equally well for items where the association with disgust is clearest to participants.

Furthermore, the traditional indices were explicitly associated with state disgust (except in SM-BATs). This is not surprising since these indices are conceptually closely related to directly experienced disgust for specific items. More interestingly, the non-specific DPSS-R correlated significantly with experienced disgust during AR- and IP-BATs as well.

It has been proposed that all disgust domains have originally evolved from core disgust (Rozin et al., 2009). If so, then the further these have evolved from core disgust (e.g., IP, SM), the less clear the association with disgust might be to (lay) participants. Especially, since (lay) participants may define 'disgust' differently than experimenters (Nabi, 2002). Thus, when measuring disgust irrespective of specific elicitors, the strongest associations should be found for the central forms of disgust (core, AR). Accordingly, the DPSSR-subscales correlated relatively strongly with core and AR-BATperformance, slightly lower with IP-BAT-performance, and weakly with SM-BAT-performance. Yet, none of the disgust propensity indices were associated with the SM-BATS. The pattern differed somewhat for disgust propensity and sensitivity regarding the separate BAT-domains (e.g., DPSS-RP correlated low with IP-BAT-performance, while DPSS-RS did not). However, since correlations between disgust propensity and BAT-performance were slightly higher in general, this may reflect a quantitative rather than a qualitative difference. Attesting to this claim, disgust propensity and sensitivity did not independently predict overall behavioral avoidance.

The prediction that disgust sensitivity contributes to propensity in motivating behavioral avoidance was not confirmed. Although correlations between the DPSS-R-subscales confirmed that it measures two separate constructs (e.g., Fergus \& Valentiner, 2009), under the present circumstances, both disgust traits could not be distinguished as separate predictors of behavioral avoidance. Yet, under other circumstances, disgust sensitivity may contribute to feelings of aversion or fear of specific disgust-elicitors (e.g., vomit in emetophobia; van Overveld et al., 2008).

Future research should take several issues into account. First, the range of the DPSS-RS in the present sample may not have been sufficiently extreme to test whether elevated disgust sensitivity influences behavioral withdrawal tendencies. The finding that both mean and maximum-scores (11 in a range of 6-30) for disgust sensitivity were relatively low is consistent with this view.

Second, researchers should consider their research goals closely in order to determine whether a stimulus-dependent (DES, DS) or stimulus-independent (DPSS-R) index of disgust propensity is the most appropriate. Not all participants who are disgusted more readily will be disgusted more readily of all the items incorporated in the DES/DS.

In conclusion, in disgust research, an index is necessary that does not suffer from content overlap with indices of psychopathology. The present findings sustain the suggestion that the DPSS-R is such an index with sound psychometric features. Lastly, the DPSS-R provided complementary information compared to traditional disgust indices and may measure a more broad and general construct of disgust propensity than stimulus-dependent indices.

\section{Appendix A}

See Table A1.
Table A1

Disgust Propensity and Sensitivity Scale - Revised (DPSS-R). Instructions: this questionnaire consists of 12 statements about disgust. Please read each statement and think how often it is true for you, then place a ' $\mathrm{x}$ ' in the box that is closest to this.

\begin{tabular}{ll}
\hline & \\
\hline 1 & I avoid disgusting things \\
2 & When I feel disgusted, \\
I worry that I might pass out & Some Often Always \\
3 & It scares me when I feel nauseous \\
4 & I feel repulsed \\
5 & Disgusting things make my stomach \\
& turn \\
6 & I screw up my face in disgust \\
7 & When I notice that I feel nauseous, I \\
& worry about vomiting \\
8 & I experience disgust \\
9 & It scares me when I feel faint \\
10 & I find something disgusting \\
11 & It embarrasses me when I feel \\
disgusted &
\end{tabular}

Scoring key: never $=1$, rarely $=2$, sometimes $=3$, often $=4$, always $=5$.

Disgust propensity: sum of items $1,4,5,6,8,10$.

Disgust sensitivity: sum of items 2, 3, 7, 9, 11, 12 .

\section{References}

Bland, J. M., \& Altman, D. G. (1997). Statistics notes: Cronbach's alpha. British Medical Journal, 314, 572.

Cavanagh, K., \& Davey, G. C. L. (2000). The development of a measure of individual differences in disgust. Paper presented to the British psychological society, Winchester, UK.

Deacon, B., \& Olatunji, B. O. (2007). Specificity of disgust sensitivity in the prediction of behavioral avoidance in contamination fear. Behaviour Research and Therapy, $45,2110-2120$

de Jong, P. J., \& Muris, P. (2002). Spider phobia: Interaction of disgust and perceived likelihood of involuntary physical contact. Journal of Anxiety Disorders, 16 51-65.

de Jong, P. J., van Overveld, M., Weijmar Schultz, W., Peters, M. L., \& Buwalda, F. (2009). Disgust and contamination sensitivity in vaginismus and dyspareunia. Archives of Sexual Behavior, 38, 244-252.

Fergus, T. A., \& Valentiner, D. P. (2009). The Disgust Propensity and Sensitivity Scale - Revised: An examination of a reduced-item version. Journal of Anxiety Disorders, 23, 703-710.

Haidt, J., McCauley, C., \& Rozin, P. (1994). Individual differences in sensitivity to disgust: A scale sampling seven domains of disgust elicitors. Personality and Individual Differences, 16, 701-713.

Kaye, T. (1998). American History X [motion picture]. United States: New Line Cinema.

Koch, M. D., O'Neill, K., Sawchuk, C. N., \& Connolly, K. (2002). Domain-specific and generalized disgust sensitivity in blood-injection phobia: The application of behavioral approach/avoidance tasks. Journal of Anxiety Disorders, 16, 511-527.

Matchett, G., \& Davey, G. C. L. (1991). A test of disease-avoidance model of animal phobias. Behaviour Research and Therapy, 29, 91-94.

Mulkens, S. A. N., de Jong, P. J., \& Merckelbach, H. (1996). Disgust and spider phobia. Journal of Abnormal Psychology, 105, 464-468.

Nabi, R. L. (2002). The theoretical versus the lay meaning of disgust: Implications for emotion research. Cognition and Emotion, 16, 695-703.

Olatunji, B. O., Cisler, J. M., Deacon, B. J., Connolly, K., \& Lohr, J. M. (2007a). The Disgust Propensity and Sensitivity Scale - Revised: Psychometric properties and specificity in relation to anxiety disorder symptoms. Journal of Anxiety Disorders, 21, 918-930.

Olatunji, B. O., Moretz, M. W., Bjorklund, F., de Jong, P. J., Haidt, J., Hursti, T. J., et al. (2009). Confirming the three-factor structure of the Disgust Scale - Revised in eight countries. Journal of Cross-Cultural Psychology, 40, 234-255.

Olatunji, B. O., Williams, N. L., Lohr, J. M., \& Sawchuk, C. N. (2005). The structure of disgust: Domain specificity in relation to contamination ideation and excessive washing. Behaviour Research and Therapy, 43, 1069-1086.

Olatunji, B. O., Williams, N. L., Tolin, D. F., Abramowitz, J. S., Sawchuk, C. N., Lohr, J. M., et al. (2007b). The Disgust Scale: Item analysis, factor structure, and suggestions for refinement. Psychological Assessment, 19, 281-297.

van Overveld, W. J. M., de Jong, P. J., Peters, M. L., Cavanagh, K., \& Davey, G. C. L. (2006). Disgust propensity and disgust sensitivity: Separate constructs that are differentially related to specific fears. Personality and Individual Differences, 41, 1241-1252.

van Overveld, M., de Jong, P. J., Peters, M. L., van Hout, W. J. P. J., \& Bouman, T. K. (2008). An internet-based study on the relation between disgust sensitivity and emetophobia. Journal of Anxiety Disorders, 22, 524-531. 
Page, A. C. (1994). Blood-injury phobia. Clinical Psychology Review, 14, 443-461. Rozin, P., Fallon, A. E., \& Mandell, R. (1984). Family resemblance in attitudes to food. Developmental Psychology, 20, 309-314.

Rozin, P., Haidt, J., \& McCauley, C. R. (2009). Disgust: The body and soul emotion in the 21st century. In B. O. Olatunji \& D. McKay (Eds.), Disgust and its disorders: Theory, assessment, and treatment implications. Washington, DC: American Psychological Association.

Rozin, P., Haidt, J., McCauley, C., Dunlop, L., \& Ashmore, M. (1999). Individua differences in disgust sensitivity: Comparisons and evaluations of paper-and- pencil versus behavioral measures. Journal of Research in Personality, 33, 330-351.

Solondz, T. (1998). Happiness [motion picture]. United States: Good Machine.

Tsao, S. D., \& McKay, D. (2004). Behavioral avoidance tests and disgust in contamination fears: distinctions from trait anxiety. Behaviour Research and Therapy, 42, 207-216.

Walls, M. M., \& Kleinknecht, R. A. (1996). Disgust factors as predictors of bloodinjury fear and fainting. Paper presented at the annual meeting of the Western Psychological Association, San Jose, CA. 